Ethical approval: The Swedish survey was approved by the ethical committee of the University of Linköping. The Russian survey was of non-medical nature and ethical approval was not required.

1 Leon DA, Chenet L, Shkolnikov V, Zakharov S, Shapiro J, Rakhmanova G, et al. Huge variation in Russian mortality rates 1984-94: artefact, alcohol, or what? Lancet 1997:350:383-8.

2 Notzon FC, Komarov YM, Ermakov SP, Sempos CT, Marks JS, Sempos EV. Causes of declining life expectancy in Russia. JAMA 1998;279:793-

3 Tunstall-Pedoe H, Kuulasmaa K, Amouyel P, Arveiler D, Rajakangas AM, Pajak A. Myocardial infarction and coronary deaths in the World Health Organization MONICA project. Registration procedures, event rates, and case-fatality rates in 38 populations from 21 countries in four continents. Circulation 1994;90:583-612.

4 Tunstall-Pedoe H, Kuulasmaa K, Mahonen M, Tolonen H, Ruokokoski E, Amouyel P, et al. Contribution of trends in survival and coronary event rates to changes in coronary heart disease mortality: 10 year results from 37 WHO MONICA project populations. Lancet 1999;353:1547-57.

5 World Health Organization. WHO Statistical Information System (WHOSIS). Evidence and information for health policy. www3.who.int whosis (accessed 30 March 2004).

6 Bobak M, Pikhart H, Hertzman C, Rose R, Marmot M. Socioeconomic factors, perceived control and self-reported health in Russia. A cross-sectional survey. Soc Sci Med 1998;47:269-79.
Ware JE, Sherbourne CD. The MOS 36-item short-form health survey (SF-36). I. Conceptual framework and item selection. Med Care 1992;30:473-83

8 McHorney CA, Ware JE, Raczek AE. The MOS 36-item short-form health survey (SF-36): II. Psychometric and clinical tests of validity in measuring physical and mental health constructs. Med Care 1993;31:247-63.

9 Pudaric S, Sundquist J, Johansson SE. Country of birth, instrumental activities of daily living, self-rated health and mortality: a Swedish population-based survey of people aged 55-74. Soc Sci Med 2003:56:2493-503.

10 Kristenson M, Kucinskiene Z, Bergdahl B, Calkauskas H, Urmonas V, Orth-Gomer K. Increased psychosocial strain in Lithuanian versu Swedish men: the LiVicordia Study. Psychosom Med 1998;60:277-82.

11 Kuh D, Ben-Shlomo Y, eds. A life course approach to chronic disease epidemiology. Oxford: Oxford University Press, 1997.

2 Mathers CD, Sadana R, Salomon JA, Murray CJL, Lopez AD. Healthy life expectancy in 191 countries, 1999. Lancet 2001;357:1685-91.

13 World Health Organization. Healthy life expectancy. www3.who.int/ whosis/hale/

hale.cfm?path $=$ whosis,burden_statistics,hale\&language $=$ english (accessed 30 March 2004)

14 Fries JF. Measuring and monitoring success in compressing morbidity. Ann Intern Med 2003;139:455-9.

(Accepted 26 July 2004)

doi $10.1136 /$ bmj.38202.667130.55

\title{
The hidden curriculum in undergraduate medical education: qualitative study of medical students' perceptions of teaching
}

\author{
Heidi Lempp, Clive Seale
}

Academic

Rheumatology,

Guy's, King's and St

Thomas' School of

Medicine, King's

College London,

London SE5 9RJ

Heidi Lempp

senior qualitative

researcher

Department of

Human Sciences,

Brunel University,

Uxbridge UB8 3PH

Clive Seale

professor of sociology

Correspondence to:

H Lempp

heidi.k.lempp@

kcl.ac.uk

BMJ 2004;329:770-3

\begin{abstract}
Objective To study medical students' views about the quality of the teaching they receive during their undergraduate training, especially in terms of the hidden curriculum.

Design Semistructured interviews with individual students.

Setting One medical school in the United Kingdom. Participants 36 undergraduate medical students, across all stages of their training, selected by random and quota sampling, stratified by sex and ethnicity, with the whole medical school population as a sampling frame.
\end{abstract}

Main outcome measures Medical students'

experiences and perceptions of the quality of teaching received during their undergraduate training.

Results Students reported many examples of positive role models and effective, approachable teachers, with valued characteristics perceived according to traditional gendered stereotypes. They also described a hierarchical and competitive atmosphere in the medical school, in which haphazard instruction and teaching by humiliation occur, especially during the clinical training years.

Conclusions Following on from the recent reforms of the manifest curriculum, the hidden curriculum now needs attention to produce the necessary fundamental changes in the culture of undergraduate medical education.

\section{Introduction}

The development of medical education has been described as a history of reform without change. ${ }^{1}$
Hidden curriculum: the set of influences that function at the level of organisational structure and culture including, for example, implicit rules to survive the institution such as customs, rituals, and taken for granted aspects

During the past decade, all UK medical schools have implemented reforms to the manifest (overt) undergraduate curriculum, with changes to course content, teaching methods, and examinations. ${ }^{2}$ However, there has been less attention to the hidden curriculum, which has emerged as an influential concept in medical education. ${ }^{3-6}$ This refers to the "processes, pressures and constraints which fall outside ... the formal curriculum, and which are often unarticulated or unexplored.” It has been argued that hidden aspects of the curriculum are especially important in professional education, which characteristically includes prolonged periods of exposure to the predominant culture..$^{6-9}$

The hidden curriculum has been described in relation to training of house officers or residents, ${ }^{10}$ general medical education, ${ }^{4}{ }^{71}$ dental education, ${ }^{12}$ and nursing education. ${ }^{13}$ Six learning processes of the hidden curriculum of medical education have been identified loss of idealism, ${ }^{5}$ adoption of a "ritualised" professional identity, ${ }^{5}$ emotional neutralisation, ${ }^{14}$ change of ethical integrity, ${ }^{15}$ acceptance of hierarchy, ${ }^{7}$ and the learning of less formal aspects of "good doctoring." ${ }^{16}$ Together they achieve the enculturation of students as they

The semistructured interview is on bmj.com 
develop into both practitioners and members of the medical profession.

\section{Methods}

We undertook a qualitative investigation of the content of the hidden curriculum and how it is delivered to medical students. Full details of the method are available elsewhere. ${ }^{17}$ In brief, the study cohort consisted of 36 students in years 1-5 in one medical school in the United Kingdom (table); recruitment was stopped when saturation was reached for the key study themes. The students were selected by random and quota sampling, stratified by sex and ethnicity to ensure that the views of these groups were represented, with the whole student population of the medical school as the sampling frame. Thirteen students refused to participate, and the 36 respondents did not differ in key characteristics from the whole medical student population of the medical school.

Qualitative data were collected in one to one semistructured interviews (see bmj.com), which took place in a private room in the medical school. We transcribed the interviews, identified emerging and repeated themes, and used NVivo and Concordance software to conduct content and discourse analysis, with simple counting methods. ${ }^{18}$ Validity checks included plausibility of the accounts in the experience of the authors; seeking clarification and examples of key points during the interviews; and paying attention to negative instances. Each medical student gave written informed consent to participate in the study.

\section{Results}

Four main themes emerged: personal encouragement, haphazard teaching, the importance of hierarchy, and getting ahead by being competitive.

\section{Personal encouragement}

Among the 36 students, 26 identified 46 specific staff members as positive role models who had an encouraging and motivating impact on them. These teachers' commitment to teaching and to communicating with students, patients, and colleagues were highly rated. As one student put it:

There have been a couple of lecturers that I have thought were very good ... One of them was one of my tutors as well so I got to know them personally, and he's a really nice bloke ... good lecturers-approachable and you can chat to them about anything else. (Year 2 student)

Most of the role models mentioned were male doctors $(27 / 46)$, who were seen particularly valued in relation to their knowledge, professional power, and authority. The female medical role models (19/46) were said to convey more "human" attributes: tolerance, integrity, respectfulness, and support towards students. Only two of the 46 named role models were non-white, although 14 of the 36 students were themselves non-white.

Enthusiastic about her discipline, involved students actively in the work, excellent knowledge and practical skills, nice to patients, staff, and students. (Year 5 student)

\section{Haphazard teaching}

Most students (25/36) described the haphazard nature of teaching, particularly by clinical staff, who often dis-
Characteristics of study cohort (36 participants)

\begin{tabular}{|c|c|c|c|}
\hline Characteristic & No & Characteristic & No \\
\hline Training stage: & & Family status: & \\
\hline Year 1 or 2 & 13 & Single & 33 \\
\hline Year 3 or 4 & 16 & Engaged & 1 \\
\hline Year 5 & 7 & Married & 2 \\
\hline$\overline{\text { Sex: }}$ & & Has children & 0 \\
\hline Female & 21 & Place of birth: & \\
\hline Male & 15 & United Kingdom & 30 \\
\hline Mean age (years) & 23 & Other Europe & 1 \\
\hline Ethnicity (self described): & & Outside Europe & 5 \\
\hline White & 20 & Religion: & \\
\hline Indian & 4 & None & 16 \\
\hline Bangladeshi & 2 & Christian & 9 \\
\hline Black & 2 & Muslim & 9 \\
\hline Pakistani & 2 & Hindu & 1 \\
\hline African-Asian & 1 & Jewish & 1 \\
\hline Arab & 1 & Entry to medical school: & \\
\hline Chinese & 1 & After school & 18 \\
\hline Irish & 1 & After gap year & 6 \\
\hline Jewish & 1 & One year off and other activies & 3 \\
\hline \multirow[t]{2}{*}{ Persian } & 1 & Mature & 9 \\
\hline & & $\begin{array}{l}\text { Obtained intercalated while at } \\
\text { medical school }\end{array}$ & 7 \\
\hline
\end{tabular}

regarded the overt timetable. Twenty students indicated that unscheduled changes to teaching sessions were time wasting and very common. Final year students $(6 / 7)$ were especially critical of what they perceived as a lack of commitment and poor teaching skills in some teachers. Despite this, most students gave a series of excuses to explain teachers' absence from educational sessions. Often students were profoundly demotivated by their perception that many clinical teachers had a low level of commitment to teaching, and this led to a repetitive cycle of non-attendance by students and teachers alike.

I mean we've had so many days where we've had, sort of, five different sessions scheduled-and no one turns up! You just think, you know, why bother coming in? So that's irritating. It does happen a lot to everyone. I mean, obviously the people who are teaching have another job-it's not their only job to teach you-but it's when you turn up and they don't get somebody else to do it, or they don't even let you know that they haven't turned up. (Year 3 student)

\section{Importance of hierarchy}

One of the principal ways in which students learnt about the importance of hierarchy in medicine is through teaching that involved humiliation, a feature noted in previous studies. ${ }^{5}$ In total, 21/36 students reported 29 incidents of humiliation: 10 they had observed or heard about and 19 direct personal experiences, particularly during their clinical years. Almost all the reported perpetrators were male doctors (28/29 incidents). Typically the incidents occurred in ward rounds, when students were unable to answer the same repeated question (11 incidents) or when they were criticised for an inadequate clinical examination (8 incidents). In three quarters of the incidents (21/29) the perpetrators were senior medical staff. Again, students often reported excuses for such behaviour by senior teaching staff or blamed themselves for these events.

I've found my first rotation was very stressful, humiliating, I worked and read because of fear, because of being targeted-and that was just miserable ... One time, the con- 
sultant came in when I was examining the patient-his registrar was there, his $\mathrm{SHO}$ was there and just started asking me questions ... I just went blank and didn't know the answers to his questions-and then he got angrier ... after things like that ... you don't even have the confidence to take blood or anything. (Year 3 student)

There were also several reports of nurses and midwives treating medical students disrespectfully (15/23 clinical students). Such behaviour may indicate a degree of professional rivalry. ${ }^{5}{ }^{5}$

When, I think, you go to a teaching hospital, you're again, you know: "Oh, it's a medical student turned up on the wards!" The nurses go: "Cor blimey," you know, "here's another one!" Some of them actually try and give you a hard time ... the midwives especially ... they'll fob you off ... most male medical students, you know, when they do obs and gynae, they'll have this totally biased opinion of midwiveswhich I do at the moment as well. They are the women from hell! (Year 5 student)

\section{Getting ahead by being competitive}

Half of the students (18/36) reported that competition rather than cooperation is the defining characteristic of medicine, a view that was more common among clinical students $(16 / 23)$ than non-clinical students (2/13). Related to this, for 13/36 students one "module" of the hidden curriculum concerned the need to impress senior medical staff, which was directly seen to prepare the way for prestigious jobs in the future. More subtly, some students used phrases during the interviews which implied some advantage over other students. For example, 5/9 mature students reported at the beginning of the interview that they already had a degree or professional qualification. A student reflected on this atmosphere:

You notice that students during the clinical years try to stand out, stabbing each other. (Year 3 student)

\section{Discussion}

This study relies on interview accounts rather than observation of actual teaching. Secret observations, which are perhaps ethically unacceptable, would be necessary for further verification of students' accounts. An added limitation of this study is the fact that data were collected from only one medical school. This means that there is some potential for contamination between students' accounts, although this was unlikely because fewer than $2 \%$ of all students at that medical school were interviewed. Even so, their reports suggest a worrying lack of accountability of medical teachers in overstretched clinical settings. The absence of any consistent formal system of monitoring in UK medical schools is currently under review in relation to the General Medical Council ${ }^{1}$ and the Quality Assurance Agency, although a system of peer review is gradually being introduced.

Medical education has largely escaped from the quality control rigours imposed on clinical practice. In part this may be because clinical practice and research have long dominated the attention of doctors, and teaching has been considered a lesser activity, without clear incentives or career structures. Indeed, relatively few doctors have received formal training in teaching methods, educational theories, or modes of assessment. ${ }^{20}$ The Dearing report of inquiry into higher education ${ }^{21}$ highlighted this as a deficiency for all teachers employed in universities, not only in medicine, and

\section{What is already known on this topic}

The manifest undergraduate medical curriculum has undergone major changes in recent years in Britain

Less attention has been paid to the impact, process, and structure of the hidden curriculum, and how these are experienced by medical students

\section{What this study adds}

Many students report positive and effective role models, but with valued characteristics perceived according to traditional gendered stereotypes among teachers

Students often report a hierarchical and competitive atmosphere in which haphazard tuition and teaching by humiliation continue to occur

Recognition and reform of the hidden curriculum is required to achieve the necessary fundamental changes to the culture of undergraduate medical education

made clear recommendations, which have been endorsed by the General Medical Council. ${ }^{22}$ For this reason Leinster has proposed creating a proper system of rewards for teaching, a formal structure of accountability and monitoring within medical schools, a recognised teaching qualification, financial allocations for identified teaching sessions, and the provision of dedicated administrative staff to minimise the time doctors lose from patient care and research. ${ }^{23}$ Teaching could then be incorporated in the job plans of consultants and reviewed as part of their annual appraisals.

Although some NHS trusts have introduced measures intended to stamp out bullying among staff members ${ }^{24}$ these measures have not yet been widely adopted within teaching hospitals. Indeed, this would involve a change in the core organisational culture and identity of medicine. Such policies could be framed in terms of "zero tolerance" towards the humiliation of students, made explicit in the contracts of teaching staff, with workable ways to allow confidential reporting of such behaviour without damage to the career prospects of whistleblowers.

Further studies of the hidden curriculum from other medical schools are needed, including the perspectives of clinical teachers, to assess the generalisability of our findings. For example, rapid changes in the ethnic composition and sex ratio of medical students may have important implications for medical education, and understanding these can result in evidence based changes to the hidden as well as the manifest curriculum in future.

We are grateful to all the students who participated in the study, for their time and openness. We also acknowledge the valuable contributions of the senior staff at the medical school who supported this research. This study was carried out while HL was a PhD student in the Department of Sociology, Goldmiths College, University of London.

Contributors: HL designed the study and carried out interviews and the data analysis. CS advised on study design and data 
analysis. Both wrote the paper. Caroline Ramazanoglu assisted at an early stage of the study, Kate Nash provided invaluable advice and support, and Floss Chittenden provided unfailing support with the transcriptions of the interviews. HL is guarantor.

Funding: None

Competing interests: None declared.

Ethical approval: The full relevant requirements for the ethical conduct of research, as set out by the British Sociology Association (www.britsoc.co.uk/Library/Ethicsguidelines2002.doc), were strictly adhered to.

1 Bloom SW. The medical school as a social organisation: the source of resistance to change. Med Educ 1989;23: 228-41.

2 General Medical Council Tomonois doctors: recommendations on undergraduate medical education. London: GMC, 1993

3 Hafferty FW, Franks R. The hidden curriculum, ethics teaching, and the structure of medical education. Acad Med 1994;69:861-71.

Hafferty FW. Beyond curriculum reform: confronting medicine's hidden curriculum. Acad Med 1998;73:403-7.

5 Sinclair S. Making doctors. An institutional apprenticeship. Oxford: Berg, 1997

6 Cribb A, Bignold S. Towards the reflexive medical school: the hidden curriculum and medical education research. Stud Higher Educ 1999;24: 195-209.

7 Hafferty FW. Reconfiguring the sociology of medical education: emerging topics and pressing issues. In: Bird F, Conrad P, Fremont AM, eds. Handbook of medical sociology, 5th ed. New York: Prentice Hall, eds. Handbook

Bloom SW. Innocence in education. School Rev 1972;80:333-59.

9 Assor A, Gordon D. The implicit learning theory of hidden curriculum research. J Curric Stud 1987;19:329-39.

10 Anderson DJ. The hidden curriculum. Am J Roent 1992;159:21-2.

11 Marinker M. Myth, paradox and the hidden curriculum. Med Educ 2001;31:293-8.

12 DeSchepper EJ. The hidden curriculum in dental education. J Dent Educ 1987:51:575-7.

13 Mayson J, Hayward W. Learning to be a nurse: the contribution of the hidden curriculum in the clinical setting. Nurse Pract N Z 1997;12:16-22

4 Helman C. The dissection room. In: Body Myths. London: Chatto and Windus, 1991:114-23.

15 Coldicott Y, Pope C, Roberts C. The ethics of intimate examinationsteaching tomorrow's doctors. BMJ 2003;326:97-101.

16 Wright S, Kern DE, Kolodner K, Howard DE, Brancati FL. Attributes of excellent attending-physician role models. $N$ Engl J Med 1998:339: 1986-93.

17 Lempp HK. Undergraduate medical education: a transition from medical student to pre-registration doctor [dissertation]. London: Goldsmiths College, University of London, 2004.

18 Seale C. The quality of qualitative research. Introducing qualitative methods. London: Sage, 1999: 119-39.

19 Savage J. What is happening to nursing? BMJ 1995;311:274-5.
20 Seabrook MA. Medical teachers' concerns about the clinical teaching context. Med Educ 2003;37:213-22.

21 Dearing R. Summary report: the National Committee of Inquiry into Higher Education. Norwich:HMSO, 1997

22 General Medical Council. Tomorrow's doctors: recommendations on undergraduate medical education. London: GMC, 2002.

23 Leinster SJ. Medical education in the real world. Med Educ 2003;37:397-8.

24 Hicks B. How can a deanery win the battle against bullying? BMJ Careers 2003;326(suppl):S129. http://careerfocus.bmijournals.com/cgi/content/ full/326/7393/S129

\section{Corrections and clarifications}

Spinal immobilisation for unconscious patients with multiple injuries

One keystroke occluded the identity of the second author of this clinical review by $\mathrm{C} \mathrm{G}$ Morris and colleagues (28 August, pp 495-9), leading to Eamon Paul McCoy being listed as W McCoy. The correct designation of the authors is $\mathrm{C}$ G Morris, $\mathrm{E}$ P McCoy, G G Lavery. The bmj.com versions have been amended.

Lassa fever: epidemiology, clinical features, and social consequences

A further small error has belatedly come to light in this clinical review by J Kay Richmond and Deborah J Baglole (BMJ 2003;327:1271-5). Reference 12 should have read: Bausch D. Lassa fever in Sierra Leone. London: World Health Organization, 2000 (that is, not published by Merlin, as was stated).

Hospital at home for patients with acute exacerbations of chronic obstructive pulmonary disease: systematic review of evidence

The authors of this paper, Felix S F Ram and colleagues, point out that they should have said that a longer version of their review (7 August, pp 315-8) is available in the Cochrane Library (Ram FSF, Wedzicha JA, Wright J, Greenstone M. Hospital at home for acute exacerbations of chronic obstructive pulmonary disease. Cochrane Database Syst Rev 2004;(3):CD003573).

\section{Testing hypotheses}

Medicine is the natural home of the untested hypothesis, says Hugh Pennington while wondering why doctors are so unscientific. ${ }^{1}$ When the pain started to go down my left arm, one day some four years ago, I considered my family history of heart disease and came to the obvious conclusion. So the next day I cycled from University College London to the Royal Free Hospital, up Hampstead Hill, to my relief without a twinge. With the angina hypothesis disproved, I could safely ignore the pain, which was conveniently intermittent if unpredictable, and get on with a busy job.

Digging up a tree root changed everything. The pain worsened, but subsided with the cocktail of paracetamol and ibuprofen that I recommend to so many patients, so I could carry on hacking and heaving. Carrying heavy bags on a holiday journey further tested my second hypothesis-muscle sprain-and I was able to experience the peculiar apprehension that comes with being ill away from home. Then the escalating pain, interrupted sleep, and diminished power in the left arm demolished the muscle hypothesis and replaced it with a neurological one. A colleague in neurology diagnosed a cervical disc prolapse, confirmed by magnetic resonance imaging.

I was soon back on my bike, although I gave tree roots a wide berth, with just the occasional dart of pain and, more often, odd tingles in the hand or forearm. Thus, when the arm throbbed at the start of a tennis match just before Easter I put it down to the neck problem and carried on. The feeling disappeared, only to recur the next day as I was cycling up a relatively gentle incline, but it stopped when I reached level ground and did not recur when I cycled home. The dodgy disc hypothesis held, and I dug out some analgesia in case I needed it.

That night I could not sleep for the pain in my arm. Paracetamol did not touch the pain, and, as it spread across the chest and I began to feel nauseated, I finally realised that the disc was innocent. The emergency services moved quickly, and the hospital departments dealt with the incident with great skill. Undergoing an emergency coronary artery bypass graft is an education, particularly if you have no major risk factors for heart disease (the "family history" now being attributed to smoking rather than genetics).

Back on my bike again and even eyeing a tree root in need of extraction, I understand that medicine is the natural home of hypothesis testing, but that we do not test hypotheses under circumstances of our own choosing but according to our hopes, fears, and competing demands.

Steve Iliffe senior partner, Lonsdale Medical Centre, London (s.iliffe@pcps.ucl.ac.uk)

1 Pennington H. Why can't doctors be more scientific? London Review of Books 2004;26(13):28-9 